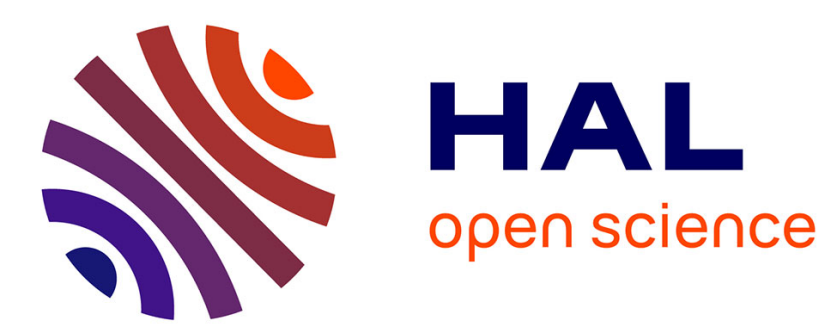

\title{
Influence of magnetite stoichiometry on the binding of emerging organic contaminants
}

\author{
Wei Cheng, Remi Marsac, Khalil Hanna
}

\section{To cite this version:}

Wei Cheng, Remi Marsac, Khalil Hanna. Influence of magnetite stoichiometry on the binding of emerging organic contaminants. Environmental Science and Technology, 2018, 52 (2), pp.467-473. 10.1021/acs.est.7b04849 . insu-01662350

\section{HAL Id: insu-01662350 https://hal-insu.archives-ouvertes.fr/insu-01662350}

Submitted on 13 Dec 2017

HAL is a multi-disciplinary open access archive for the deposit and dissemination of scientific research documents, whether they are published or not. The documents may come from teaching and research institutions in France or abroad, or from public or private research centers.
L'archive ouverte pluridisciplinaire HAL, est destinée au dépôt et à la diffusion de documents scientifiques de niveau recherche, publiés ou non, émanant des établissements d'enseignement et de recherche français ou étrangers, des laboratoires publics ou privés. 


\section{Influence of magnetite stoichiometry on the binding of emerging organic contaminants \\ Wei Cheng, Rémi Marsac, and Khalil Hanna}

Environ. Sci. Technol., Just Accepted Manuscript • DOI: 10.1021/acs.est.7b04849 • Publication Date (Web): 07 Dec 2017

Downloaded from http://pubs.acs.org on December 13, 2017

\section{Just Accepted}

"Just Accepted" manuscripts have been peer-reviewed and accepted for publication. They are posted online prior to technical editing, formatting for publication and author proofing. The American Chemical Society provides "Just Accepted" as a free service to the research community to expedite the dissemination of scientific material as soon as possible after acceptance. "Just Accepted" manuscripts appear in full in PDF format accompanied by an HTML abstract. "Just Accepted" manuscripts have been fully peer reviewed, but should not be considered the official version of record. They are accessible to all readers and citable by the Digital Object Identifier (DOI®). "Just Accepted" is an optional service offered to authors. Therefore, the "Just Accepted" Web site may not include all articles that will be published in the journal. After a manuscript is technically edited and formatted, it will be removed from the "Just Accepted" Web site and published as an ASAP article. Note that technical editing may introduce minor changes to the manuscript text and/or graphics which could affect content, and all legal disclaimers and ethical guidelines that apply to the journal pertain. ACS cannot be held responsible for errors or consequences arising from the use of information contained in these "Just Accepted" manuscripts. 


\section{$1 \quad$ Influence of magnetite stoichiometry on the binding of emerging \\ 2 organic contaminants}

3

4

5

6 a'École Nationale Supérieure de Chimie de Rennes, UMR CNRS 6226, 11 Allée de Beaulieu, 7

8

4

\author{
Wei Cheng ${ }^{a}$, Rémi Marsac ${ }^{\text {a,b }}$, Khalil Hanna ${ }^{* a}$
}

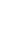
(1)

${ }^{\mathrm{b}}$ Géosciences Rennes, UMR 6118 CNRS - Université Rennes 1, Campus de Beaulieu, 35042

(1)

0

11

12

13

14
35708 Rennes Cedex 7, France

Rennes Cedex, France

*Corresponding author: Tel.: +33 2232380 27; fax: +33 223238120 .

E-mail address: khalil.hanna@ensc-rennes.fr (K. Hanna)

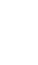

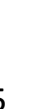

15 \\ 16}

17

\author{
A revised manuscript for ES\&T
}

December 2017 


\section{Abstract}

19 While the magnetite stoichiometry (i.e. $\mathrm{Fe}(\mathrm{II}) / \mathrm{Fe}(\mathrm{III})$ ratio) has been extensively studied for the reductive transformation of chlorinated or nitroaromatic compounds, no work exists

21 examining the influence of stoichiometry of magnetite on its binding properties. This study, for the first time, demonstrates that the stoichiometry strongly affects the capacity of magnetite to bind not only quinolone antibiotics such as nalidixic acid (NA) and Flumequine (FLU), but also salicylic acid (SA), natural organic matter (humic acid, HA) and dissolved silicates. Fe(II)-amendment of non-stoichiometric magnetite $(\mathrm{Fe}(\mathrm{II}) / \mathrm{Fe}(\mathrm{III})=0.40)$ led to similar sorbed amounts of NA, FLU, SA, silicates or HA as compared to the stoichiometric magnetite (i.e. $\mathrm{Fe}(\mathrm{II}) / \mathrm{Fe}(\mathrm{III})=0.50)$. At any $\mathrm{pH}$ between 6 and 10, all magnetites exhibiting similar $\mathrm{Fe}(\mathrm{II}) / \mathrm{Fe}(\mathrm{III})$ ratio in the solid phase showed similar adsorption properties for NA or FLU. This enhancement in binding capability of magnetite for NA is still observed in presence of environmentally relevant ligands (e.g. $10 \mathrm{mg} \mathrm{L}^{-1}$ of HA or $100 \mu \mathrm{M}$ of silicates). Using surface complexation modeling, it was shown that the NA-magnetite complexation constant does not vary with $\mathrm{Fe}(\mathrm{II}) / \mathrm{Fe}(\mathrm{III})$ between 0.24 and 0.40 , but increases by 8 orders of magnitude when $\mathrm{Fe}(\mathrm{II}) / \mathrm{Fe}(\mathrm{III})$ increases from 0.40 to 0.50 . 
34 I. Introduction

Magnetite is an ubiquitous mixed Fe(II)-Fe(III) oxide in soils and sediments, and is very efficient in environmental remediation owing to its reduction capacity. ${ }^{1,2}$ For this reason, the reactivity of magnetite to reduce various organic ${ }^{3-7}$ and inorganic contaminants ${ }^{8-11}$ has been extensively studied. The stoichiometry of the particles (i.e. $\mathrm{Fe}(\mathrm{II}) / \mathrm{Fe}(\mathrm{III})$ ratio that can vary from 0 to 0.5 ) is one of the most important factors in the reduction reaction, and could govern the reactivity of magnetite in natural systems. ${ }^{6,10,11}$ Exposing non-stoichiometric magnetite (i.e. low $\mathrm{Fe}(\mathrm{II}) / \mathrm{Fe}(\mathrm{III})$ ratio) to a source of $\mathrm{Fe}(\mathrm{II})$ can restore the 0.5 ratio (i.e. perfectly stoichiometric magnetite) through oxidation of adsorbed Fe(II), accompanied by reduction of the octahedral $\mathrm{Fe}(\mathrm{III})$ in the underlying magnetite to octahedral $\mathrm{Fe}(\mathrm{II}){ }^{5,6}$ Therefore, investigations to recharge magnetite surfaces by $\mathrm{Fe}(\mathrm{II})$ in order to enhance its reactivity as well as the effect of magnetite stoichiometry on the reduction of contaminants have attracted great attention. ${ }^{4-7}$ However, very little is known about the impact of Fe(II)-recharge on adsorption properties of the magnetite surface. Although the magnetite adsorption capacity was evaluated for different compounds including heavy metals and radionuclides, ${ }^{2,12,13}$ oxyanions ${ }^{14,15}$ and organic ligands, ${ }^{16}$ none has attempted to assess the influence of $\mathrm{Fe}(\mathrm{II}) / \mathrm{Fe}(\mathrm{III})$ ratio on the mechanism and extent of binding of these compounds on magnetite surfaces.

In this work, we elucidate these effects in different magnetite suspensions containing Nalidixic Acid (NA) or Flumequine (FLU) (see their structures and speciation in Fig. S1). Because of their growing use in human and veterinary medicine and continuous release into the environment, quinolone antibiotics such as NA and FLU have been detected in surface waters, groundwaters and sediments at concentrations levels ranging from $\mathrm{ng} \mathrm{L}^{-1}$ to $\mu \mathrm{g} \mathrm{L}^{-1}$. ${ }^{17-}$

19 As the mobility of these compounds in the environment can be strongly affected by interactions with surfaces of soil and sediment mineral particles ${ }^{18-19}$, a thorough 
understanding of their sorption behavior is essential. Magnetite and more generally iron (oxy)(hydr)oxides represent important reactive surfaces towards organic ligands in soils and sediments.

Here, we examined both ligand adsorption and $\mathrm{Fe}(\mathrm{II})$ dissolution as a function of $\mathrm{pH}$ for magnetites exhibiting different $\mathrm{Fe}(\mathrm{II}) / \mathrm{Fe}(\mathrm{III})$ ratio, prepared as such, or through $\mathrm{Fe}(\mathrm{II})$ recharge of non-stoichiometric magnetite suspensions. The binding capability of magnetite with respect to $\mathrm{Fe}(\mathrm{II}) / \mathrm{Fe}(\mathrm{III})$ ratio was also examined in presence of naturally occurring ligands (e.g. salicylic acid (SA), silicates and humic acid (HA)). Implication of ternary surface complexation (i.e. surface-metal-ligand complex) in enhancement in ligand adsorption was assessed by investigating the impact of other divalent cations ( $\mathrm{Mn}(\mathrm{II}), \mathrm{Ni}(\mathrm{II})$ ) on NA adsorption, where metal binding with no electron transfer is supposed to occur on magnetite. We then used surface complexation modeling to describe the observed behavior, and to gain further insights into the mechanisms responsible for enhancing ligand sorption upon Fe(II)recharge. The present work notably revealed a considerable impact of the magnetite stoichiometry on the sorption capability of magnetite surfaces.

\section{Experimental}

Chemicals. If not mentioned, chemicals (all pro analytical quality or better) were obtained from Sigma Aldrich. Leonardite Humic Acid standard (LHA) was purchased from the International Humic Substances Society (IHSS). Solutions were prepared with ultrapure "MilliQ" water (specific resistivity, $18.2 \mathrm{M} \Omega \mathrm{cm}^{-1}$ ) purged with $\mathrm{N}_{2}$ for $4 \mathrm{~h}$. Magnetite (ideal formula: $\mathrm{Fe}_{3} \mathrm{O}_{4}$ ) was synthesized applying a procedure involving a room temperature aqueous precipitation method in an anaerobic chamber (JACOMEX). A $0.3 \mathrm{M} \mathrm{HCl}$ solution containing a $\mathrm{FeCl}_{2}: \mathrm{FeCl}_{3}$ 1:2 molar ratio was introduced into an $\mathrm{N}_{2}$-sparged 25\% w/v ammonium $\left(\mathrm{NH}_{4} \mathrm{OH}\right)$ solution, with continuous stirring at $1400 \mathrm{rpm}$, leading to instantaneous 
84 precipitation of magnetite particles. Because washing steps can lead to the loss of Fe(II), ${ }^{6}$ no washing step was applied to obtain the stoichiometric magnetite (M0.50; the number refers to $\mathrm{Fe}(\mathrm{II}) / \mathrm{Fe}(\mathrm{III})$ ratio). The solid concentration was $25 \mathrm{~g} \mathrm{~L}^{-1}(5 \mathrm{~g}$ in $200 \mathrm{~mL})$ and the $\mathrm{pH}$ was 8.3 . Other magnetites, Fe(II)-depleted, were obtained from M0.50. By applying one washing step to a fraction of M0.50 suspension with $\mathrm{N}_{2}$-purged ultrapure water and then centrifuged for 5 min at $4000 \mathrm{rpm}, \mathrm{M} 0.44$ was obtained. By applying three washing steps to M0.50, M0.40 or M0.42 can be obtained. By exposing the M0.50 during 24h to a known amount of $\mathrm{H}_{2} \mathrm{O}_{2}$ (following the procedure of Gorski et al. ${ }^{6}$ ), M0.42 (denoted as M0.42- $\mathrm{H}_{2} \mathrm{O}_{2}$ ) and M0.33 were obtained. By exposing the M0.50 during 24h to ambient air, M0.24 was obtained.

Characterization of magnetite particles. The mineral identify was confirmed by X-ray diffraction (see XRD pattern in Fig. S2). According to TEM micrographs (Fig. S2), the synthetic magnetite particles are 10 to $15 \mathrm{~nm}$ in diameter (12.5 $\mathrm{nm}$ on average). Similar XRD patterns were found for the different magnetites investigated here, and no notable influence of the stoichiometry of the particles on particle size was observed. Accordingly, B.E.T. surface area did not significantly differ between the magnetites used in this study $\left(89 \pm 4 \mathrm{~m}^{2} \mathrm{~g}^{-1}\right)$. Using the assumption that all magnetite particles are spherical in shape (density $=5.15 \times 10^{6} \mathrm{~g}$ $\left.\mathrm{m}^{-3}\right)^{1}$, TEM surface area was determined to be $93 \mathrm{~m}^{2} \mathrm{~g}^{-1}$ close to the BET one.

An aliquot of each magnetite suspension was taken and digested in $\mathrm{N}_{2}$-sparged $5 \mathrm{M} \mathrm{HCl}$ inside the glovebox overnight with shaking. Dissolved Fe(II) and Fe(III) concentrations were then determined using the phenanthroline method. ${ }^{20}$ This bulk Fe(II) content was found very close to that determined by acid digestion on the filtered solid, as previously reported. ${ }^{5,6}$ The amount of magnetite bound-Fe(II) $\left([\mathrm{Fe}(\mathrm{II})]_{\text {bound }}=[\mathrm{Fe}(\mathrm{II})]_{\mathrm{tot}}-[\mathrm{Fe}(\mathrm{II})]_{\mathrm{aq}}\right)$ was used to calculate the effective $\mathrm{Fe}(\mathrm{II}) / \mathrm{Fe}(\mathrm{III})$ ratio (denoted as $(\mathrm{Fe}(\mathrm{II}) / \mathrm{Fe}(\mathrm{III}))_{\text {bound }}$ ) in magnetite which was shown to vary with $\mathrm{pH}$ (see results and discussion section). [ $\mathrm{Fe}(\mathrm{II})]_{\text {tot }}$ is the total concentration 
of $\mathrm{Fe}(\mathrm{II})$ in the suspension (solid + solution) and $[\mathrm{Fe}(\mathrm{II})]_{\mathrm{aq}}$ is the dissolved concentration of $\mathrm{Fe}(\mathrm{II})$, measured after filtration $(0.2 \mu \mathrm{m}$, Whatman $)$ of the magnetite suspension.

Adsorption experiments. Adsorption batch experiments were carried out in $15 \mathrm{~mL}$ polypropylene tubes under anaerobic conditions (glovebox). $\mathrm{NaCl}$ concentration was set to 10 $\mathrm{mM}$ for all experiments. The effect of dissolved Fe(II) on NA or FLU adsorption to magnetite was investigated by adding small amounts of $100 \mathrm{mM} \mathrm{FeCl}_{2}$ solution (dissolved in $0.1 \mathrm{M}$ $\mathrm{HCl}$ ). $\mathrm{pH}$ was adjusted using $0.1 \mathrm{M} \mathrm{NaOH} / \mathrm{HCl}$ solutions. After $24 \mathrm{~h}$ reaction time, an aliquot was taken and filtered $(0.2 \mu \mathrm{m}$, Whatman $)$ for high performance liquid chromatography analysis with UV-vis detection (HPLC-UV) and dissolved Fe(II) analysis by the phenanthroline method. Aqueous concentrations of NA or FLU were determined using HPLC (Waters 600 Controller) equipped with a reversed-phase C18 column ( $250 \mathrm{~mm} \times 4.6 \mathrm{~mm}$ i.d., 5 $\mu \mathrm{m}$ ) and a UV-vis detector (Waters 2489). The mobile phase was mixture of acetonitrile/water $(60 / 40 \mathrm{v} / \mathrm{v})$ contained $0.1 \%$ formic acid. The flow rate was set at $1 \mathrm{ml} \mathrm{min} \mathrm{m}^{-1}$ in isocratic mode. The UV detector was set to $258 \mathrm{~nm}$ for NA and $246 \mathrm{~nm}$ for FLU.

Note that kinetic experiments at $\mathrm{pH}=8.5$ revealed that (i) NA binding to magnetite (M0.50 or M0.42) and Fe(II) uptake by M0.42 occurred within less than 5 minutes and (ii) the order of adding chemicals (i.e. addition of NA to $24 \mathrm{~h}$ pre-equilibrated M0.42 with $\mathrm{Fe}(\mathrm{II})$ or addition of $\mathrm{Fe}(\mathrm{II})$ to $24 \mathrm{~h}$ pre-equilibrated M0.42 with NA) had no impact on the binding behavior (See Fig. S3). NA adsorption isotherms on M0.50 and M0.42 were also investigated at $\mathrm{pH}=7(20 \leq[\mathrm{NA}] \leq 300 \mu \mathrm{M})$.

The same procedure was applied to test the effect of $\mathrm{Mn}(\mathrm{II})$ and $\mathrm{Ni}(\mathrm{II})$ on NA adsorption to M0.40. Dissolved Mn(II) and Ni(II) concentrations were determined by Atomic absorption spectroscopy (AAS, Shimadzu). The effect of $10 \mathrm{mg} \mathrm{L}^{-1} \mathrm{HA}$ or $100 \mu \mathrm{M}$ silicates on the adsorption of $20 \mu \mathrm{M}$ NA to magnetite was also investigated, applying the same procedure. HA concentrations in solution were monitored using an organic carbon analyzer (Shimadzu 
TOC-VCSH). SA concentration was determined using UV-Visible spectrophotometer at 297 $\mathrm{nm}$. Silicates concentrations were determined by the molybdenum-blue colorimetric method. ${ }^{21}$ Surface complexation modeling. The geochemical speciation code PHREEQC (version 2$)^{22}$ and the "minteq" database provided with this code were used. At infinite dilution, the $\mathrm{pK}_{\mathrm{a}}$ of NA and FLU equal 6.19 and 6.31, respectively, and the logarithm of the formation constant of $\mathrm{NA}_{-} \mathrm{Fe}^{+}{ }_{\text {(aq) }}$ and $\mathrm{FLU}_{-} \mathrm{Fe}^{+}{ }_{\text {(aq) }}$ equal 3.99 and 4.23, respectively ; as calculated from reported conditional constant values and the Davies equation. ${ }^{23,24}$ The surface complexation models developed by Jolsterå et al. ${ }^{25}$ for magnetite and maghemite were used to predict NA and FLU adsorption to magnetite with different stoichiometry. Maghemite $\gamma-\mathrm{Fe}^{\mathrm{III}}{ }_{2} \mathrm{O}_{3}$ is considered as an extreme example of a non-stoichiometric magnetite $\left(\mathrm{Fe}_{1}^{\mathrm{II}} \mathrm{Fe}^{\mathrm{III}}{ }_{2} \mathrm{O}_{4}\right)$, with only $\mathrm{Fe}^{\mathrm{III}}$ in both tetrahedral and octahedral sites ${ }^{1}$.

Surface site protonation is formulated as follows (2-pKa approach):

$\equiv \mathrm{FeOH}_{2}^{+} \rightleftharpoons \equiv \mathrm{FeOH}+\mathrm{H}^{+} \quad ; \mathrm{pKa}_{, 1}$

$\equiv \mathrm{FeOH} \rightleftharpoons \equiv \mathrm{FeO}^{-}+\mathrm{H}^{+} \quad ; \mathrm{pKa}_{, 2}$

Charge-potential relationship is described according to the constant capacitance model (CCM). Model parameters for magnetite and maghemite are reported in Table S1. The CCM is not implemented in PHREEQC, but it can be used via a three plane model (TPM; available in PHREEQC), in which one capacitor and the diffuse layer are suppressed, following the procedure detailed in Marsac et al. ${ }^{26}$.

\section{Results and discussion}

Binding capacity vs magnetite stoichiometry. Nalidixic acid (NA) adsorption to four magnetites exhibiting different $\mathrm{Fe}(\mathrm{II}) / \mathrm{Fe}(\mathrm{III})$ ratio $(0.40,0.42,0.44$ and 0.50$)$ showed that NA adsorption was strongly related to the stoichiometry of the particles (i.e. $\mathrm{Fe}(\mathrm{II}) / \mathrm{Fe}(\mathrm{III})$ ratio vary from 0.40 for non-stoichiometric magnetite, to 0.50 for stoichiometric magnetite; Fig. 
1a). NA adsorption to M0.40 decreased with increasing $\mathrm{pH}$, as typically encountered for anionic ligands, and became negligible for $\mathrm{pH}>7.5$. Indeed, adsorption of anionic ligands to mineral oxides is typically greatest under acidic to circumneutral $\mathrm{pH}$, and lowest under alkaline conditions, with maximum adsorption generally observed at a $\mathrm{pH}$ near the $\mathrm{pK}_{\mathrm{a}}$ (i.e. 6.19 for NA). ${ }^{27-31}$ At higher stoichiometry $(0.42,0.44$ or 0.50$), \mathrm{pH}$ dependence of NA sorption was significantly altered. NA adsorption increased from $\mathrm{pH} 6$ to $7<\mathrm{pH}<8$ and then decreased with increasing $\mathrm{pH}$, thereby shifting the maximum $\mathrm{NA}$ adsorption to larger $\mathrm{pH}$ values than the $\mathrm{pK}_{\mathrm{a}}$. Note that adsorption of NA to M0.42 prepared either by washing or oxidizing $\left(\mathrm{H}_{2} \mathrm{O}_{2}\right)$ of M0.50 was similar. The data are merged in Fig. 1a (see Fig. S4 for more details).

Fe(II)-amendement of non-stoichiometric magnetite (M0.40 and M0.42) led also to an enhancement in NA adsorption (Fig. 1a). Indeed, the pH-adsorption curve of NA shifted to larger $\mathrm{pH}$ values with increasing added amounts of dissolved Fe(II), a result suggesting that NA binding was closely related to the $\mathrm{Fe}(\mathrm{II})$ content or $\mathrm{Fe}(\mathrm{II}) / \mathrm{Fe}(\mathrm{III})$ ratio in magnetite. The $\mathrm{Fe}(\mathrm{II})$ recharge of non-stoichiometric magnetite provided the same adsorption capability as for the corresponding magnetite with higher stoichiometry on the whole $\mathrm{pH}$-range investigated (i.e. $\mathrm{Fe}(\mathrm{II}) / \mathrm{Fe}(\mathrm{III})=0.42$ for $\mathrm{M} 0.40+100 \mu \mathrm{M} \mathrm{Fe}(\mathrm{II})$ and $\mathrm{M} 0.42 ; \mathrm{Fe}(\mathrm{II}) / \mathrm{Fe}(\mathrm{III})=$ 0.44 for M0.40 + 200 $\mu \mathrm{M} \mathrm{Fe}(\mathrm{II})$ and M0.44 $; \mathrm{Fe}(\mathrm{II}) / \mathrm{Fe}(\mathrm{III})=0.50$ for $\mathrm{M} 0.40+500 \mu \mathrm{M} \mathrm{Fe}(\mathrm{II})$, $\mathrm{M} 0.42+400 \mu \mathrm{M}$ Fe(II) and M0.50).

Because of $\mathrm{Fe}(\mathrm{II})$ dissolution, the amount of bound-Fe(II) in magnetite can vary depending on $\mathrm{pH}$, which may affect the NA adsorption. Indeed, $[\mathrm{Fe}(\mathrm{II})]_{\mathrm{aq}}$ increased with decreasing $\mathrm{pH}$ (no dissolved $\mathrm{Fe}(\mathrm{III})$ was found), due to the $\mathrm{H}^{+}$promoted dissolution of magnetite, ${ }^{32,33}$ but also with magnetite stoichiometry (i.e. M0.40<M0.44 $<$ M0.50) (Figure 1b). Exposing a non-stoichiometric magnetite (M0.40) to 200 or $500 \mu \mathrm{M}$ Fe(II) led to similar $\mathrm{Fe}(\mathrm{II})$ aqueous concentration as those measured with M0.44 or M0.50, respectively. Note that 
only up to $\sim 10 \%$ of magnetite could dissolve in our experiments (e.g. for M0.50 at the lowest $\mathrm{pH}$ investigated, i.e. 6). Therefore, the effect of magnetite dissolution on NA adsorption can be neglected.

As expected, (Fe(II)/Fe(III)) bound increased with $\mathrm{Fe}(\mathrm{II})$-recharge of non-stoichiometric magnetite and $\mathrm{pH}$ (Figure 1c). Variation in $(\mathrm{Fe}(\mathrm{II}) / \mathrm{Fe}(\mathrm{III}))_{\text {bound }}$ appeared fully consistent with the magnetite ability to bind NA. For instance, all magnetites exhibiting similar $(\mathrm{Fe}(\mathrm{II}) / \mathrm{Fe}(\mathrm{III}))_{\text {bound }}$ values showed similar NA sorbed amounts whatever the investigated $\mathrm{pH}$, though the dissolved Fe(II) amounts are different (especially at low pH values $<7.5$ ) (Fig. 1b). For instance, M0.50 shows the same binding capability for NA as for the corresponding $\mathrm{Fe}(\mathrm{II})$-amended magnetite (i.e. M0.40 $+500 \mu \mathrm{M} \mathrm{Fe}(\mathrm{II})$ and $\mathrm{M} 0.42+400 \mu \mathrm{M} \mathrm{Fe}(\mathrm{II})$ ), and therefore similar surface properties with respect to NA adsorption. This is also true for M0.40 $+200 \mu \mathrm{M}$ Fe(II) vs M0.44, and further illustrated in Fig. S5, where variations of NA sorbed amounts at $\mathrm{pH} 7.7$ as a function of $(\mathrm{Fe}(\mathrm{II}) / \mathrm{Fe}(\mathrm{III}))_{\text {bound }}$ followed the same trend for both stoichiometric magnetite (M0.5) and Fe(II)-amended non-stoichiometric magnetites (M0.40 and M0.44). Likewise, enhancement in Flumequine (FLU) adsorption was observed with increasing amounts of added Fe(II) to M0.40 or (Fe(II)/Fe(III)) bound (Fig. S6). Desorption tests were conducted by adjusting $\mathrm{pH}$ to 11 after the system has reached equilibrium and then stirred for around $2 \mathrm{~h}$. Mass balance showed that NA or FLU was removed only by adsorption and that transformation by, for example, reduction, did not occur under the experimental conditions of this study.

Formation of ternary surface complexes (i.e. surface-metal-ligand complex) generally entails more ligand adsorption when complexing cation concentration increases ${ }^{34}$, which might explain the enhancement in NA or FLU binding to magnetite. To test this hypothesis, impacts of presence of two divalent cations (Mn(II) and Ni(II)) on NA adsorption to M0.40 were investigated and compared with that of $\mathrm{Fe}(\mathrm{II})$. Because the redox potential of the 
$208 \mathrm{Mn}^{\mathrm{II}} / \mathrm{MnO}_{2(\mathrm{~s})}$ couple at $\mathrm{pH}=7$ is much larger than that of $\mathrm{Fe}^{\mathrm{II}} / \mathrm{Fe}_{3} \mathrm{O}_{4(\mathrm{~s})}, \mathrm{Mn}$ (II) oxidation by

209 magnetite is not expected. ${ }^{35}$ According to the Irving-Williams series, ${ }^{36}$ cation adsorption $210 \mathrm{data}^{35}$ and aqueous complexation with $\mathrm{NA},{ }^{23,37}$ ternary surface complexation of Mn(II), Fe(II)

211 and $\mathrm{Ni}$ (II) with NA on magnetite are supposed to follow the order: $\mathrm{Mn}$ (II) $<\mathrm{Fe}$ (II) $<\mathrm{Ni}(\mathrm{II})^{34}$

212 (assuming that no electron transfer occurs between Fe(II) and the solid). This ranking is,

213 however, observed neither for metal uptake nor for NA adsorption to M0.40 (Fig. 2). Indeed,

214 more Fe(II) uptake than Ni(II) is achieved (Fig. 2a), whereas maximum NA adsorption was

215 obtained at $\mathrm{pH} \approx 7.5$ for $\mathrm{Fe}(\mathrm{II})$ and $\mathrm{pH} \approx 8.5$ for $\mathrm{Mn}(\mathrm{II})$ and $\mathrm{Ni}(\mathrm{II})$. This observation is also

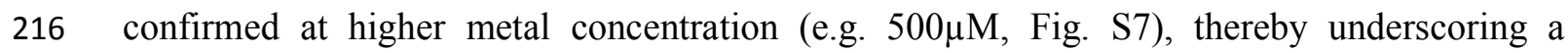

217 different adsorption behavior of NA in presence of $\mathrm{Fe}(\mathrm{II})$ with respect to other divalent

218 transition metals.

219 Taken together, these findings suggest that the adsorption enhancement for NA is mainly 220 controlled by the $(\mathrm{Fe}(\mathrm{II}) / \mathrm{Fe}(\mathrm{III}))_{\text {bound }}$ ratio in magnetite, rather than by $\mathrm{NA}-\mathrm{Fe}(\mathrm{II})$ 221 complexation in solution at low $\mathrm{pH}$ or ternary surface complexation. As a matter of fact, the 222 enhanced binding of ligands to stoichiometric magnetite with respect to non-stoichiometric 223 one may result from the creation of new binding sites upon Fe(II)-recharge, or changes in the 224 intrinsic surface reactivity of amended magnetite.

225 relationship between $(\mathrm{Fe}(\mathrm{II}) / \mathrm{Fe}(\mathrm{III}))_{\text {bound }}$ and ligand adsorption, we used a surface complexation modeling approach. The aim of the present modeling exercise was to provide a 229 semi-quantitative evaluation of how much magnetite surface reactivity towards quinolones is affected by its stoichiometry. Because of the possible presence of various types of

$231 \equiv \mathrm{Fe}{ }^{\mathrm{II} / I I \mathrm{O}} \mathrm{O}(\mathrm{H})$ groups at magnetite surfaces, full mechanistic description of binding 232 mechanisms using a complete approach would have required fitting of many parameters, and 
233 then generated large errors on simulated phenomena. Therefore, we used the 2-pKa-CCM

234 approach developed by Jolsterå et al. ${ }^{25}$. Using acid-base titration method, they have calculated 235 site densities of $1.50 \mathrm{~nm}^{-2}$ and $0.99 \mathrm{~nm}^{-2}$ for magnetite $\left(91 \mathrm{~m}^{2} \mathrm{~g}^{-1}\right)$ and maghemite $\left(86 \mathrm{~m}^{2} \mathrm{~g}^{-1}\right)$,

236

237

respectively

As shown in Figure S8, fitting experimental adsorption isotherms of NA on M0.50 and M0.42 at $\mathrm{pH}=7$ with Langmuir equation results in a maximum binding capacity of 0.95 and 0.71 NA molecule $\mathrm{nm}^{-2}$, respectively. Previous studies on quinolones binding to iron (hydr)oxides evidenced that one molecule binds to two surface hydroxo groups, ${ }^{29,38,39}$ by involving its carboxylate and its keto-group as following:

$2 \equiv \mathrm{FeOH}+2 \mathrm{H}^{+}+\mathrm{NA}^{-} \rightleftharpoons(\equiv \mathrm{Fe})_{2} \mathrm{NA}^{+}+2 \mathrm{H}_{2} \mathrm{O} \quad{ }^{\mathrm{S}} \mathrm{K}$

Hence, the maximum binding of NA to magnetites corresponds to 1.90 to 1.42 site $\mathrm{nm}^{-2}$, which are relatively close to those determined by Jolsterå et al. ${ }^{25}$. As the present modeling exercise aimed to determine surface complexation constant $\left({ }^{\mathrm{S}} \mathrm{K}\right)$ to each magnetite, we focused only on the pH-edge curve (obtained at low surface coverage) and thus used the same site density for all magnetites $\left(1.50 \mathrm{~nm}^{-2}\right)$. Measured total dissolved Fe(II) concentration in solution at the end of each adsorption experiment was used as input parameter to account for ligand-Fe(II) complexation in solution. However, decreasing ligand adsorption with decreasing $\mathrm{pH}$ (i.e. at high $[\mathrm{Fe}(\mathrm{II})]_{\mathrm{aq}}$ ) could not be well predicted, further suggesting that effects of variation of $(\mathrm{Fe}(\mathrm{II}) / \mathrm{Fe}(\mathrm{III}))_{\text {bound }}$ were more important than the ligand-Fe(II) aqueous complexation. Therefore, we only focused on data at high $\mathrm{pH}$ values, where $(\mathrm{Fe}(\mathrm{II}) / \mathrm{Fe}(\mathrm{III}))_{\text {bound }}$ is maximal and constant (see Fig. 1c; e.g. $\mathrm{pH}>8$ for $\mathrm{M} 0.50, \mathrm{pH}>6.5$ for M0.40). As shown in Figure 1a (NA) and Figure S6 (FLU), a relatively good fit to the adsorption data versus $\mathrm{pH}$ was found (unsuccessful extrapolations at lower $\mathrm{pH}$ are shown as dotted lines in Fig. 1a and S6). When plotting $\log { }^{\mathrm{S}} \mathrm{K}$ for NA versus (Fe(II)/Fe(III)) bound (Fig. 
258 3), a linear relationship was found $\left(\mathrm{R}^{2}=0.99\right)$. Data for FLU are also included and show a 259 comparable behavior. Values of $\log { }^{S} \mathrm{~K}$ increased by almost 8 orders of magnitude with 260 increasing $(\mathrm{Fe}(\mathrm{II}) / \mathrm{Fe}(\mathrm{III}))_{\text {bound }}$ from 0.40 to 0.50 , suggesting that stoichiometric magnetite 261 (Fe(II)-enriched) may have a much stronger affinity for NA or FLU than partially oxidized 262 magnetite (Fe(II)-depleted). Such large variation in $\log { }^{\mathrm{S}} \mathrm{K}$ cannot be attributed to potential 263 modification in surface site density that was neglected by using the same site density for all 264 magnetites. As more amount of $\mathrm{Fe}(\mathrm{II})$ at the magnetite surface is expected upon $\mathrm{Fe}(\mathrm{II})$ 265 recharge, we may suppose that $\equiv \mathrm{Fe}{ }^{\mathrm{II}} \mathrm{O}(\mathrm{H})$ sites are more reactive than $\equiv \mathrm{Fe}{ }^{\mathrm{III}} \mathrm{O}(\mathrm{H})$ for NA or 266 FLU binding.

To test the binding capacity of magnetite with lower stoichiometries, we prepared M0.33 and M0.24 (similar to magnetites found in some natural samples ${ }^{40,41}$ ), by exposing the M0.50 during 24h to (i) a known amount of $\mathrm{H}_{2} \mathrm{O}_{2}$ (following the procedure of Gorski et al. ${ }^{6}$ ) and (ii) ambient air, respectively. Both oxidized magnetites exhibited similar NA adsorption, whereas $[\mathrm{Fe}(\mathrm{II})]_{\mathrm{aq}}$ were found very low (Fig. 1b). For $\mathrm{pH} \leq 7$, more pronounced NA adsorption was observed on M0.33 and M0.24 as compared to M0.40, a result that can be attributed to the complete suppression of dissolved Fe(II) at low pH. Consistently, the best

274 fitting values of ${ }^{\mathrm{S}} \mathrm{K}$ were found very close for M0.24, M0.33 $\left(\log { }^{\mathrm{S}} \mathrm{K}=17.7\right)$ and M0.40 (log $\left.{ }^{\mathrm{S}} \mathrm{K}=17.5\right)$. It is worth noting that the calculated surface complexation constant ${ }^{\mathrm{S}} \mathrm{K}$ remains constant for $0.23<\mathrm{Fe}(\mathrm{II}) / \mathrm{Fe}(\mathrm{III}))_{\text {bound }}<0.40$, and then sharply increased after 0.40 (Fig. 2).

277 The existence of a threshold may be related to the surface amount of magnetite bound-Fe(II) required to trigger the enhancement of NA binding with magnetite surfaces.

Because non-stoichiometric magnetites may have oxidized magnetite/maghemite-like structure at the outermost surface (oxidation of magnetite particles is supposed to take place

281 from the surface to the core ${ }^{25}$ ), NA adsorption to magnetites with $\mathrm{Fe}(\mathrm{II}) / \mathrm{Fe}(\mathrm{III}) \leq 0.42$ was 282 also evaluated using the surface complexation model developed for maghemite (i.e. fully 
oxidized magnetite). Because of the little variation in site density, surface area and acid-base properties, $\log { }^{\mathrm{S}} \mathrm{K}$ (for NA and FLU) determined using magnetite model or maghemite model were found very similar (Fig. 4).

This modification in binding properties is not specifically limited to NA or FLU molecule, since the adsorption of naturally occurring ligands such as salicylate (1hydroxybenzoic acid, SA), humic acid (HA) and silicates ( $\mathrm{Si}$ ) was also considerably enhanced by the addition of dissolved Fe(II) to a non-stoichiometric magnetite M0.40 (See Figures S9S11). Consequently, the stoichiometry of magnetite is not only a key parameter for Fe(II) uptake $^{5}$ and contaminant reduction ${ }^{6,10,11}$ but also for the binding of emerging organic contaminants and naturally occurring ligands. Because emerging contaminants binding to magnetite might be affected by naturally occurring ligands, competitive experiments between NA and HA or Si were conducted. The presence of $100 \mu \mathrm{M}$ Si decreased NA binding to magnetite due to ligand competition, though the effect of Si on NA adsorption to M0.40 is insignificant (Fig. 4a). However, the impact of $10 \mathrm{mg} \mathrm{L}^{-1} \mathrm{HA}$ on NA binding implies both competitive (i.e. antagonistic effect) and cooperative (i.e. synergetic effect) mechanisms (Fig. 4b). Indeed, at high $\mathrm{Fe}(\mathrm{II}) / \mathrm{Fe}(\mathrm{III})$, HA effectively decreases NA binding whereas, at low $\mathrm{Fe}(\mathrm{II}) / \mathrm{Fe}(\mathrm{III}), \mathrm{NA}$ binding is enhanced in presence of HA. The latter may arise from intermolecular interactions between HA and NA, as previously observed between NA and other organic compounds at goethite surfaces, ${ }^{38,39}$ and supported by a quinolone-HA binding study. ${ }^{42}$ While further investigations are required to understand the different competitive and cooperative effects, this data further supports that (i) binding properties of magnetite is affected upon $\mathrm{Fe}(\mathrm{II})$-recharge, and (ii) this change towards adsorption of emerging contaminants is still observed in presence of naturally occurring ligands.

Environmental implications. Magnetites of differential composition and stoichiometry may exist in natural systems depending on the local redox and chemical 
conditions, particularly in Fe-rich subsurface environments or temporary flooded soils (e.g. wetlands experiencing redox potential fluctuation). ${ }^{1,2,38,39}$ Given its higher solubility and surface area-to-volume ratio, $\mathrm{Fe}(\mathrm{II})$ release and/or surface oxidation may occur for the nanosized magnetite, commonly found in environmental systems ${ }^{1}$. On the other hand, different kinds of magnetite can be obtained depending on the synthesis method, as reported in water remediation studies using magnetite as sorbent. ${ }^{27,31,32}$ Consequently, the stoichiometry of magnetite and its potential Fe(II)-enrichment or $\mathrm{Fe}(\mathrm{II})$-depletion in reaction medium should be appropriately considered in sorption and reactive transport studies. It is worth noting that the changes in binding properties of magnetite upon Fe(II)-recharge are still observed in presence of natural ligands, emphasizing the importance of the presently evidenced mechanisms in environmentally relevant conditions. Therefore, these findings call for refinements in current day modeling approaches used in the prediction of fate of organic contaminants in Fe-rich subsurface environments or magnetite-based remediation processes.

Acknowledgements. The authors gratefully acknowledge the financial support of this work by ADEME “Agence de l'Environnement et de la Maîtrise de l'Energie" $\mathrm{N}^{\circ}$ of funding decision $1472 \mathrm{C} 0030$.

Supporting Information Available. Characterization data of magnetite particles, NA and FLU aqueous speciation versus $\mathrm{pH}$, surface complexation model parameters, additional results for adsorption kinetics and isotherms, impacts of cationic metals, Si and HA on adsorption behavior. This information is available free of charge via the Internet at http://pubs.acs.org/. 


\section{References}

333

334

335

336

337

338

339

340

341

342

343

344

345

346

347

348

349

350

351

352

353

354

355

356

357

358

359

360

361

362

363

364

365

366

367

368

369

370

371

372

373

374

375

376

377

378

379

380

381

(1) Maher, B. A.; Taylor, R. M. Formation of ultrafine-grained magnetite in soils. Nature 1988, 336 (6197), 368-370.

(2) Singer, D. M.; Chatman, S. M.; Ilton, E. S.; Rosso, K. M.; Banfield, J. F.; Waychunas, G. A. U(VI) Sorption and Reduction Kinetics on the Magnetite (111) Surface. Environ. Sci. Technol. 2012, 46 (7), 3821-3830.

(3) McCormick, M. L.; Adriaens, P. Carbon Tetrachloride Transformation on the Surface of Nanoscale Biogenic Magnetite Particles. Environ. Sci. Technol. 2004, 38 (4), 1045-1053.

(4) Gregory, K. B.; Larese-Casanova, P.; Parkin, G. F.; Scherer, M. M. Abiotic Transformation of Hexahydro-1,3,5-trinitro-1,3,5-triazine by Fell Bound to Magnetite. Environ. Sci. Technol. 2004, 38 (5), 1408-1414.

(5) Gorski, C. A.; Scherer, M. M. Influence of Magnetite Stoichiometry on Fe" Uptake and Nitrobenzene Reduction. Environ. Sci. Technol. 2009, 43 (10), 3675-3680.

(6) Gorski, C. A.; Nurmi, J. T.; Tratnyek, P. G.; Hofstetter, T. B.; Scherer, M. M. Redox Behavior of Magnetite: Implications for Contaminant Reduction. Environ. Sci. Technol. 2010, 44 (1), 55-60.

(7) Klausen, J.; Troeber, S. P.; Haderlein, S. B.; Schwarzenbach, R. P. Reduction of Substituted Nitrobenzenes by Fe(II) in Aqueous Mineral Suspensions. Environ. Sci. Technol. 1995, 29 (9), 2396-2404.

(8) Scheinost, A. C.; Charlet, L. Selenite Reduction by Mackinawite, Magnetite and Siderite: XAS Characterization of Nanosized Redox Products. Environ. Sci. Technol. 2008, 42 (6), 1984-1989.

(9) Missana, T.; Alonso, U.; Scheinost, A. C.; Granizo, N.; García-Gutiérrez, M. Selenite retention by nanocrystalline magnetite: Role of adsorption, reduction and dissolution/co-precipitation processes. Geochim. Cosmochim. Acta 2009, 73 (20), 6205-6217.

(10) Huber, F.; Schild, D.; Vitova, T.; Rothe, J.; Kirsch, R.; Schäfer, T. U(VI) removal kinetics in presence of synthetic magnetite nanoparticles. Geochim. Cosmochim. Acta 2012, 96, 154-173.

(11) Latta, D. E.; Gorski, C. A.; Boyanov, M. I.; O'Loughlin, E. J.; Kemner, K. M.; Scherer, M. M. Influence of Magnetite Stoichiometry on UVI Reduction. Environ. Sci. Technol. 2012, 46 (2), 778-786.

(12) Giraldo, L.; Erto, A.; Moreno-Piraján, J. C. Magnetite nanoparticles for removal of heavy metals from aqueous solutions: synthesis and characterization. Adsorption 2013, 19 (2-4), 465-474.

(13) Catalette, H.; Dumonceau, J.; Ollar, P. Sorption of cesium, barium and europium on magnetite. J. Contam. Hydrol. 1998, 35 (1-3), 151-159.

(14) Daou, T. J.; Begin-Colin, S.; Grenèche, J. M.; Thomas, F.; Derory, A.; Bernhardt, P.; Legaré, P.; Pourroy, G. Phosphate Adsorption Properties of Magnetite-Based Nanoparticles. Chem. Mater. 2007, 19 (18), 4494-4505.

(15) Liu, C.-H.; Chuang, Y.-H.; Chen, T.-Y.; Tian, Y.; Li, H.; Wang, M.-K.; Zhang, W. Mechanism of Arsenic Adsorption on Magnetite Nanoparticles from Water: Thermodynamic and Spectroscopic Studies. Environ. Sci. Technol. 2015, 49 (13), 7726-7734.

(16) Tombácz, E.; Tóth, I. Y.; Nesztor, D.; Illés, E.; Hajdú, A.; Szekeres, M.; L.Vékás. Adsorption of organic acids on magnetite nanoparticles, $\mathrm{pH}$-dependent colloidal stability and salt tolerance. Colloids Surf. Physicochem. Eng. Asp. 2013, 435, 91-96.

(17) Heberer, T. Occurrence, fate, and removal of pharmaceutical residues in the aquatic environment: a review of recent research data. Toxicol. Lett. 2002, 131 (1-2), 5-17.

(18) Fatta-Kassinos, D.; Meric, S.; Nikolaou, A. Pharmaceutical residues in environmental waters and wastewater: current state of knowledge and future research. Anal. Bioanal. Chem. 2011, 399 (1), 251-275.

(19) Gothwal, R.; Shashidhar, T. Antibiotic Pollution in the Environment: A Review. CLEAN - Soil Air Water 2015, 43 (4), 479-489.

(20) Fortune, W. B.; Mellon, M. G. Determination of Iron with o-Phenanthroline: A Spectrophotometric Study. Ind. Eng. Chem. Anal. Ed. 1938, 10 (2), 60-64. 
(21) Mullin, J. B.; Riley, J. P. The colorimetric determination of silicate with special reference to sea and natural waters. Anal. Chim. Acta 1955, 12, 162-176.

(22) Parkhurst, D. L.; Appelo, C. A. J. User's guide to PHREEQC (Version 2) : a computer program for speciation, batch-reaction, one-dimensional transport, and inverse geochemical calculations; Water-Resources Investigations Report; USGS Numbered Series 99-4259; Water-resources Investigation Report 99-4259. USGS, Denver, Colorado., 1999; p (p. 312).

(23) Ross, D. L.; Riley, C. M. Aqueous solubilities of some variously substituted quinolone antimicrobials. Int. J. Pharm. 1990, 63 (3), 237-250.

(24) Vincent, W. R.; Schulman, S. G.; Midgley, J. M.; van Oort, W. J.; Sorel, R. H. A. Prototropic and metal complexation equilibria of nalidixic acid in the physiological pH region. Int. J. Pharm. 1981, 9 (3), 191-198.

(25) Jolsterå, R.; Gunneriusson, L.; Holmgren, A. Surface complexation modeling of Fe3O4-H+ and $\mathrm{Mg}(\mathrm{II})$ sorption onto maghemite and magnetite. J. Colloid Interface Sci. 2012, 386 (1), 260267.

(26) Marsac, R.; Banik, N. L.; Lützenkirchen, J.; Catrouillet, C.; Marquardt, C. M.; Johannesson, K. H. Modeling metal ion-humic substances complexation in highly saline conditions. Appl. Geochem. 2017, 79, 52-64.

(27) Paul, T.; Liu, J.; Machesky, M. L.; Strathmann, T. J. Adsorption of zwitterionic fluoroquinolone antibacterials to goethite: A charge distribution-multisite complexation model. J. Colloid Interface Sci. 2014, 428, 63-72.

(28) Usman, M.; Martin, S.; Cimetière, N.; Giraudet, S.; Chatain, V.; Hanna, K. Sorption of nalidixic acid onto micrometric and nanometric magnetites: Experimental study and modeling. Appl. Surf. Sci. 2014, 299, 136-145.

(29) Marsac, R.; Martin, S.; Boily, J.-F.; Hanna, K. Oxolinic Acid Binding at Goethite and Akaganéite Surfaces: Experimental Study and Modeling. Environ. Sci. Technol. 2016, 50 (2), 660-668.

(30) Hanna, K.; Boily, J.-F. Sorption of Two Naphthoic Acids to Goethite Surface under Flow through Conditions. Environ. Sci. Technol. 2010, 44 (23), 8863-8869.

(31) Rusch, B.; Hanna, K.; Humbert, B. Sorption and Transport of Salicylate in a Porous Heterogeneous Medium of Silica Quartz and Goethite. Environ. Sci. Technol. 2010, 44 (7), 2447-2453.

(32) Jolivet, J.-P.; Tronc, E. Interfacial electron transfer in colloidal spinel iron oxide. Conversion of Fe3O4- $-\mathrm{Fe} 2 \mathrm{O} 3$ in aqueous medium. J. Colloid Interface Sci. 1988, 125 (2), 688-701.

(33) White, A. F.; Peterson, M. L.; Hochella, M. F. Electrochemistry and dissolution kinetics of magnetite and ilmenite. Geochim. Cosmochim. Acta 1994, 58 (8), 1859-1875.

(34) Fein, J. B. The effects of ternary surface complexes on the adsorption of metal cations and organic acids onto mineral surfaces. In: R. Hellmann and S.A. Wood (Editors), Water-Rock Interactions, Ore Deposits, and Environmental Geochemistry: A Tribute to David A. Crerar. Geochemical Society, Special Pub. 7, p. 365-378.

(35) Stumm, W.; Morgan, J. J. Aquatic Chemistry: Chemical Equilibria and Rates in Natural Waters, 3rd ed, John Wiley \& Sons, Inc., New York.; 1996.

(36) Irving, H.; Williams, R. J. P. The stability of transition-metal complexes. J. Chem. Soc. Resumed 1953, $O(0), 3192-3210$.

(37) Timmers, K.; Sternglanz, R. Ionization and divalent cation dissociation constants of nalidixic and oxolinic acids. Bioinorg. Chem. 1978, 9 (2), 145-155.

(38) Xu, J.; Marsac, R.; Wei, C.; Wu, F.; Boily, J.-F.; Hanna, K. Co-binding of Pharmaceutical Compounds at Mineral Surfaces: Mechanistic Modeling of Binding and Cobinding of Nalidixic Acid and Niflumic Acid at Goethite Surfaces. Environ. Sci. Technol. 2017, 51 (20), 1161711624.

(39) Xu, J.; Marsac, R.; Costa, D.; Cheng, W.; Wu, F.; Boily, J.-F.; Hanna, K. Co-Binding of Pharmaceutical Compounds at Mineral Surfaces: Molecular Investigations of Dimer Formation at Goethite/Water Interfaces. Environ. Sci. Technol. 2017, 51 (15), 8343-8349. 
433

434

435

436

437

438

439

440

441

442

(40) Haggstrom, L.; Annersten, H.; Ericsson, T.; Wappling, R.; Karner, W.; Bjarman, S. Magnetic Dipolar and Electric Quadrupolar Effects on Mossbauer-Spectra. Hyperfine Interact. 1978, 5 (3), 201-214.

(41) Vandenberghe, R. E.; Hus, J. J.; Grave, E. D. Evidence from Mössbauer spectroscopy of neoformation of magnetite/maghemite in the soils of loess/paleosol sequences in China. Hyperfine Interact. 1998, 117 (1-4), 359-369.

(42) Aristilde, L.; Sposito, G. Complexes of the antimicrobial ciprofloxacin with soil, peat, and aquatic humic substances. Environ. Toxicol. Chem. 2013, 32 (7), 1467-1478. 


\section{$443 \quad$ Figure captions}

444 Figure 1. (a) NA adsorption data versus $\mathrm{pH}$ for $50 \mathrm{~m}^{2} \mathrm{~L}^{-1}$ suspensions of $\mathrm{M} 0.24, \mathrm{M} 0.33$, $445 \mathrm{M} 0.40, \mathrm{M} 0.42, \mathrm{M} 0.44, \mathrm{M} 0.5$ and Fe(II)-amended M0.40 and M0.42 versus $\mathrm{pH}$ in a $10 \mathrm{mM}$ $446 \mathrm{NaCl}+20 \mu \mathrm{M}$ NA solution, after $24 \mathrm{~h}$ reaction time. Lines correspond to surface 447 complexation modeling results (see text for more details). (b) Final Fe(II) aqueous 448 concentration $\left([\mathrm{Fe}(\mathrm{II})]_{\mathrm{aq}}\right)$ and (c) calculated $(\mathrm{Fe}(\mathrm{II}) / \mathrm{Fe}(\mathrm{III}))_{\text {bound }}$ in the corresponding 449 experiments. The same legend is used in (a), (b) and (c). The same color is used for experiments conducted with the same total $\mathrm{Fe}(\mathrm{II}) / \mathrm{Fe}(\mathrm{III})$ ratio.

Figure 2. (a) Uptake data of $200 \mu \mathrm{M} M n(I I), F e(I I)$ or Ni(II) on M0.40 and (b) corresponding NA adsorption data versus pH. Experimental conditions: $50 \mathrm{~m}^{2} \mathrm{~L}^{-1}$ suspensions of magnetite, $10 \mathrm{mM} \mathrm{NaCl}, 20 \mu \mathrm{M}$ NA, $200 \mu \mathrm{M} \mathrm{Mn}(\mathrm{II}), \mathrm{Fe}(\mathrm{II})$ or Ni(II), 24h reaction time. Negative values for $\mathrm{Fe}(\mathrm{II})$ uptake at low $\mathrm{pH}$ are due to magnetite dissolution.

455

Figure 3. Logarithm of surface complexation constant $\left(\log { }^{\mathrm{S}} \mathrm{K}\right.$, for NA or FLU) versus $(\mathrm{Fe}(\mathrm{II}) / \mathrm{Fe}(\mathrm{III}))_{\text {bound }}$ determined at $\mathrm{pH} \geq 8$ (where $(\mathrm{Fe}(\mathrm{II}) / \mathrm{Fe}(\mathrm{III}))_{\text {bound }}$ is constant). This modeling data was obtained using either a magnetite model (for all data) or maghemite (for $\mathrm{Fe}(\mathrm{II}) / \mathrm{Fe}(\mathrm{III}) \leq 0.42)^{25}$

Figure 4. NA adsorption data versus $\mathrm{pH}$ for $50 \mathrm{~m}^{2} \mathrm{~L}^{-1}$ suspensions of $\mathrm{M} 0.40$ and $\mathrm{Fe}(\mathrm{II})-$ amended $\mathrm{M} 0.40$ in a $10 \mathrm{mM} \mathrm{NaCl}+20 \mu \mathrm{M}$ NA solution, after $24 \mathrm{~h}$ reaction time, in presence of (a) silicates $(100 \mu \mathrm{M})$ or (b) HA $\left(10 \mathrm{mg} \mathrm{L}^{-1}\right)$. Empty symbols represent the NA adsorption data without Si or HA. 

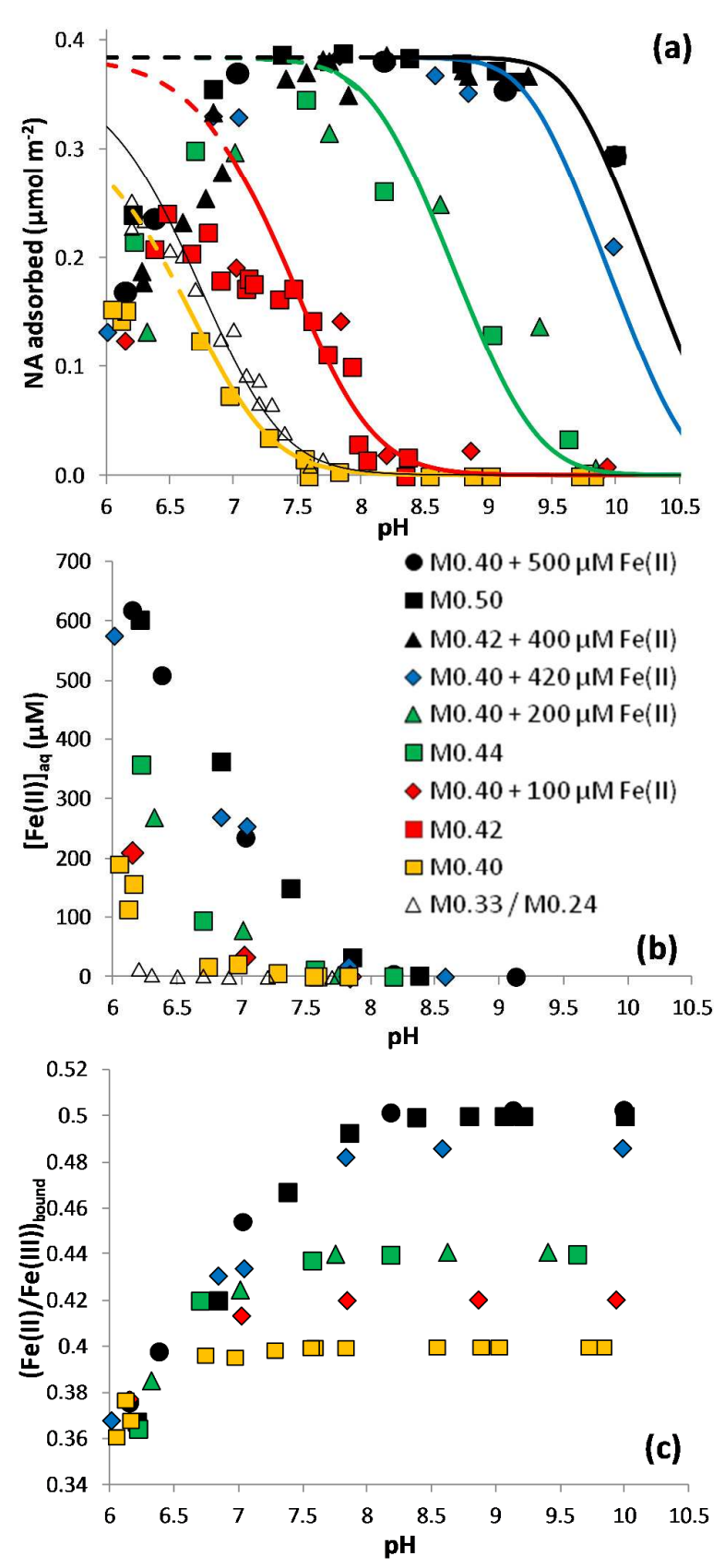

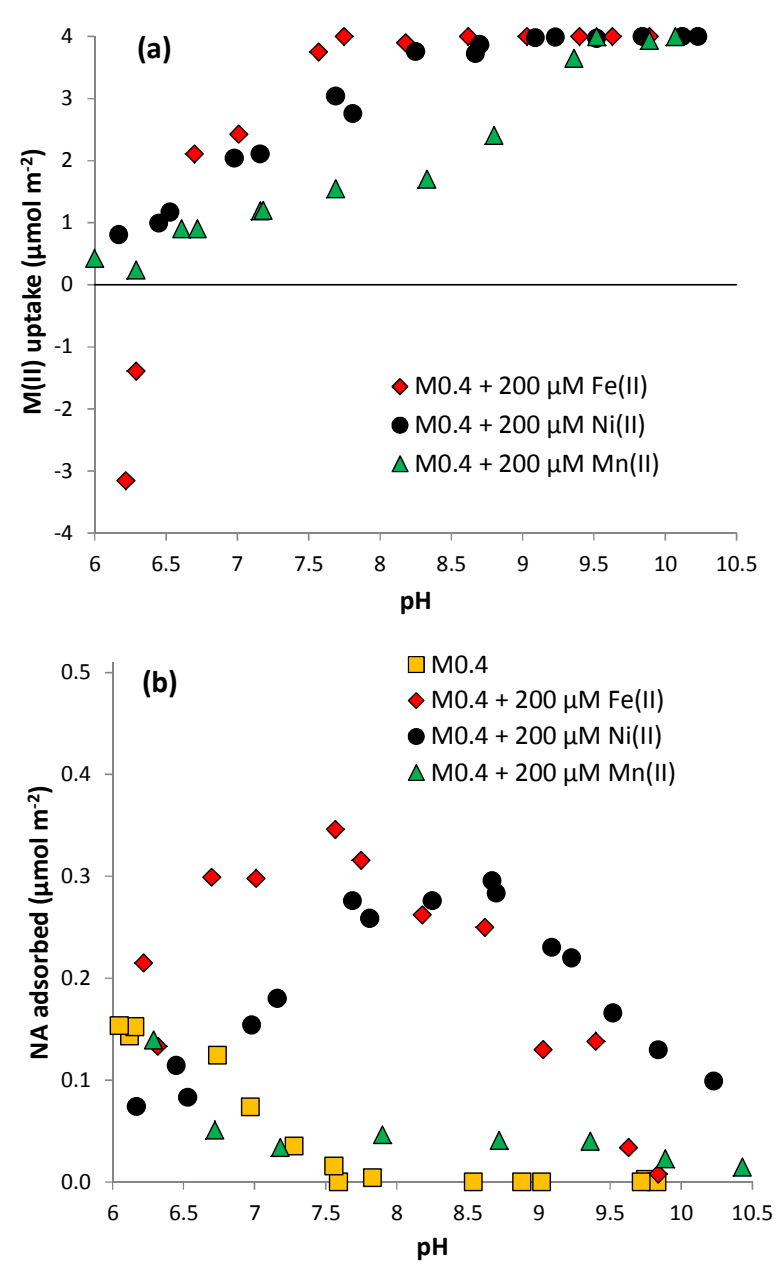


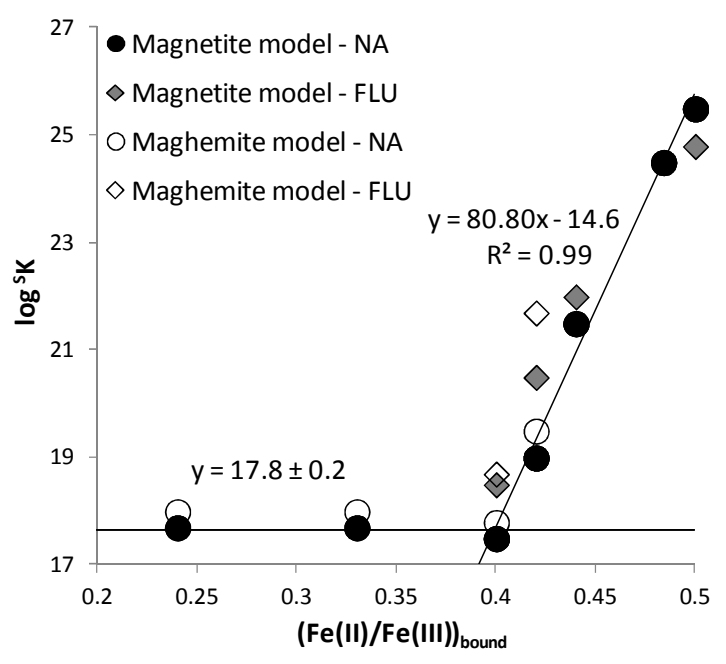

472

Figure 3

473 

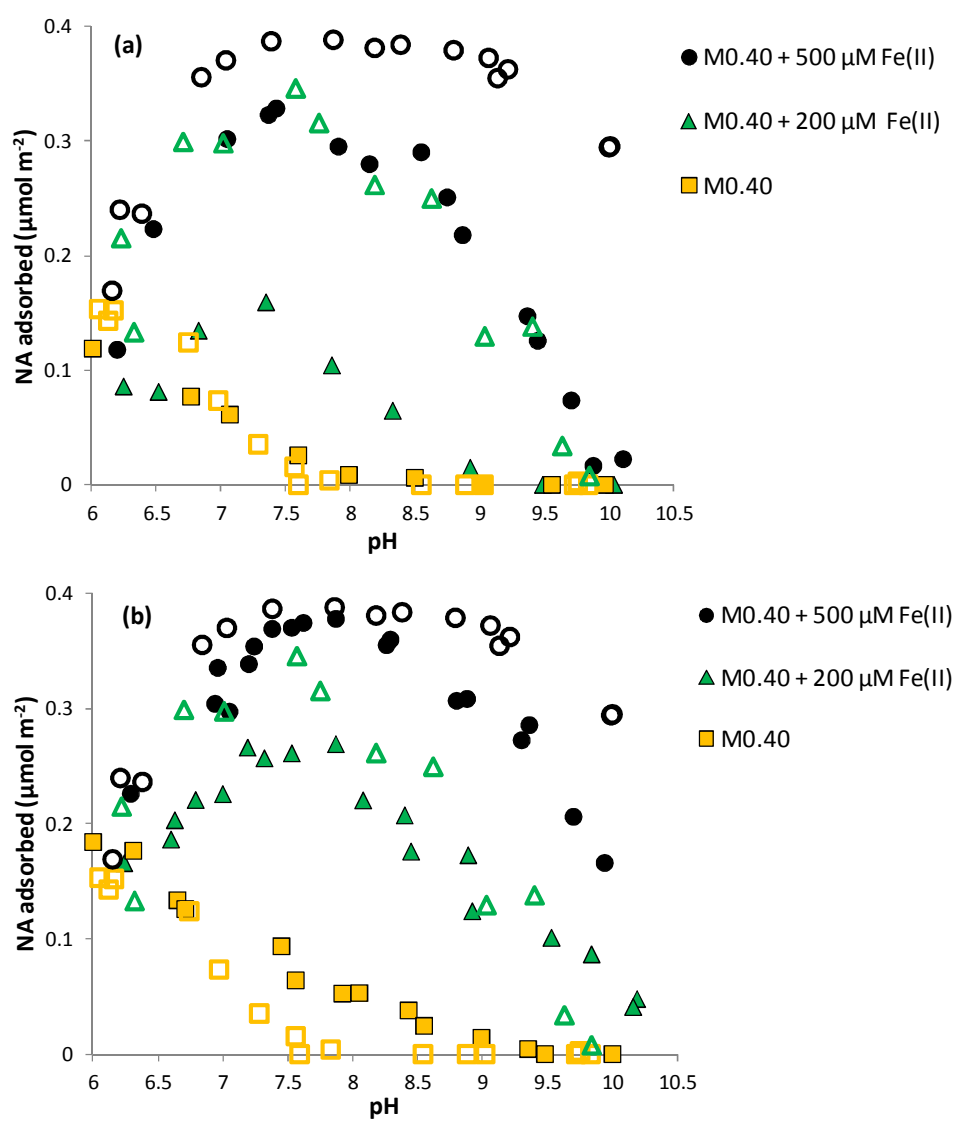

476

477

Figure 4

478 


\section{TOC}

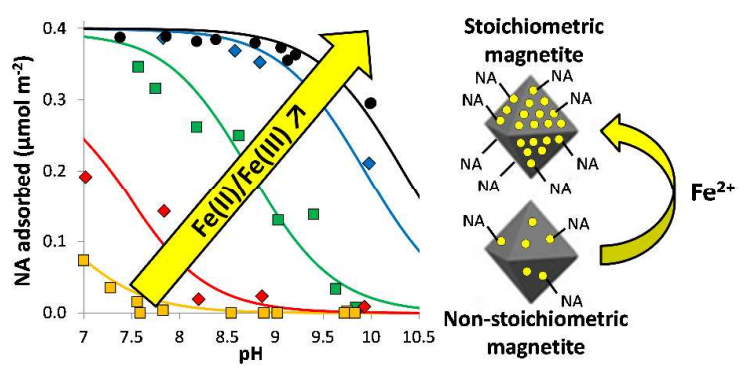

481

482

483 